\title{
AIAA 2000-3726 \\ BENCHMARK OF FDNS CFD CODE FOR DIRECT CONNECT RBCC TEST DATA
}

\author{
J. H. RUF
}

NASA Marshall Space Flight Center

Huntsville, AL

\section{$36^{\text {th }}$ AIAA/ASME/SAE/ASEE JOINT PROPULSION CONFERENCE 16-19 JULY, 2000 / HUNTSVILLE, AL.}




\title{
BENCHMARK OF FDNS CFD CODE FOR DIRECT CONNECT RBCC TEST DATA
}

\author{
Joseph H. Ruf* \\ NASA Marshall Space Flight Center, Huntsville, Alabama 35812 \\ Email: joe.ruf@msfc.nasa.gov
}

\begin{abstract}
Computational Fluid Dynamics (CFD) analysis results are compared with experimental data from the Pennsylvania State University's (PSU) Propulsion Engineering Research Center (PERC) rocket based combined cycle (RBCC) rocket-ejector experiments. The PERC RBCC experimental hardware was in a directconnect configuration in diffusion and afterburning (DAB) operation. The objective of the present work was to validate the Finite Difference Navier Stokes (FDNS) CFD code for the rocket-ejector mode internal fluid mechanics and combustion phenomena. A second objective was determine the best application procedures to use FDNS as a predictive/engineering tool. Threedimensional CFD analysis was performed. Solution methodology and grid requirements are discussed. CFD results are compared to experimental data for static pressure, Raman Spectroscopy species distribution data and RBCC net thrust and specified impulse.
\end{abstract}

$\mathrm{d}=$ duct height, $12.7 \mathrm{~cm}(5 \mathrm{in}$.

$\mathrm{h}=$ horizontal position

$\mathrm{x}=$ axial position

\section{Introduction}

RBCC engine flow path development has in the past and will in the future depend on CFD analysis to provide insight to RBCC internal fluid physics. CFD will be used in multiple ways. It will be used to assess flow path performance and perform trade studies such as afterburner fueling parametrics. CFD will also be used to define flow path environments that hardware will be required to survive. Therefore, the accuracy of these CFD codes must be determined through detailed comparisons with representative test data such as that produced by PSU.

The PERC RBCC test hardware is a single rocket, twodimensional design (Fig. 1) with variable geometry to enable studies of RBCC mixing and secondary combustion phenomena. Gaseous hydrogen (GH2) and gaseous oxygen (GO2) were used as rocket propellants with $\mathrm{GH} 2$ injection at the end of the diffuser section for DAB testing. The direct connect configuration supplied a known quantity of air to the head end of the RBCC duct'. These direct connect experiments simulate an RBCC in rocketejector mode at Mach 1 at 9,400ft and Mach 1.9 at 40,000ft for a nominal $4.8 \mathrm{e}+4 \mathrm{~N} / \mathrm{m}^{2}(1000 \mathrm{psf})$ dynamic pressure trajectory.

This analysis benchmarks the FDNS CFD code for DAB operation of the RBCC rocket-ejector mode at a simulated Mach 1 trajectory point. Previous computational work benchmarked the FDNS code for DAB operation of the RBCC rocket-ejector mode at a sea level static (Mach $0)$ trajectory point ${ }^{2}$.

\section{PSU Experimental Hardware \& Test Conditions}

The PSU direct connect RBCC hardware is shown in Fig. 1. Air is supplied at the left hand side of the hardware through four $2.54 \mathrm{~cm}$ ( 1 in.) diameter orifices. The entire RBCC duct is $7.62 \mathrm{~cm}$ ( $3 \mathrm{in}$.) deep. The mixer and diffuser sections are $89.9 \mathrm{~cm}$ (35 in.) long. The height is $12.7 \mathrm{~cm} \mathrm{(5}$ in.) but increases to $25.4 \mathrm{~cm}(10 \mathrm{in}$.) in the diffuser. The converging nozzle's throat height is 12.7 (5 in.). The rocket was operated stoichiometric with $\mathrm{GO} 2$ and $\mathrm{GH} 2$ at $3.447 \mathrm{e}+06 \mathrm{~N} / \mathrm{m}^{2}(500 \mathrm{psia})$. It has a slot throat $0.254 \mathrm{~cm}$ (0.1 in.) high by $7.62 \mathrm{~cm}$ ( 3 in.) wide and expands to an area ratio of 6 . GH2 was injected through fourteen 0.254 $\mathrm{cm}(0.1$ in.) diameter orifices in the afterburner section.

Static pressures and heat flux were measured on the top and side walls the length of the RBCC duct. Total thrust was measured with a load cell. Raman spectroscopy measurements of the major species $(\mathrm{H} 2 \mathrm{O}, \mathrm{O} 2, \mathrm{~N} 2, \mathrm{H} 2)$ in the flow field were made at five window locations in the mixer section.

Copyright $@ 2000$ by the American Institute of Aeronautics and Astronautics, Inc. No copyright is asserted in the United States under Title 17, U.S. Code The U.S. Government has a royalty-free license to exercise all rights under the copyright claimed herein for Governmental purposes. All other rights are reserved by the copyright owner.

- Member AlAA 
Solution Algorithm

\section{Approach}

FDNS is a general purpose, multidimensional, multispecies, viscous flow, pressure-based reacting flow solver. It was developed at Marshall Space Flight Center (MSFC) and is continually being improved by MSFC personnel and its supporting contractors. The code solves the Reynolds-averaged transport equations with a variety of options for physical models and boundary conditions. To solve the system of nonlinear partial differential equations, the code uses finite-difference approximations to establish a system of linearized algebraic equations. Several difference schemes were employed to approximate the convective terms of the momentum, energy and continuity equations, including central difference ${ }^{3}$, upwind and total-variationdiminishing (TVD) schemes ${ }^{4}$.

Viscous fluxes and source terms are discretized using a central-difference approximation. A pressure-based predictor plus multiple-corrector solution method is employed so that flow over a wide speed range (from low subsonic to supersonic) can be analyzed. The basic idea of this pressure-based method is to perform corrections for the pressure and velocity fields by solving a pressure correction equation so that velocity and pressure coupling is enforced, based on the continuity constraint at the end of each iteration.

An extended two-equation turbulence model $^{5}$ closure is used to describe the turbulent flow. The compressibility effect on the turbulence is taken into account by the method of Mach-number correction. A modified wall function approach ${ }^{6}$ is employed by incorporating a complete velocity profile ${ }^{7}$ This complete velocity profile provides a smooth transition between Logarithmic law-of-the-wall and linear viscous sublayer velocity distributions. Details of the present numerical methodology are given by Ref $3 .^{8}$

The present analysis was solved steady state, implementing the third order TVD scheme and an extended two-equation turbulence model with compressibility correction. The $\mathrm{GO} 2 / \mathrm{GH} 2$ combustion physics are solved finite rate with a system of seven species and nine reactions ${ }^{9}$.

\section{Grid Description}

The description of the grid given in the following paragraphs was the result of several grid density parametrics. These parametrics, not described here, determined the minimum number of nodes required in each direction to produce a grid independent solution.

The computational domain consists of one quarter of the experimental hardware internal flow path. Symmetry planes were used on the vertical and horizontal centerlines. The structured grid had approximately 570,000 nodes in 12 zones. Non-matching zonal boundaries were implemented at several locations to keep the number of nodes from becoming excessive. Table 1 lists the number of nodes in each zone. The I, J, $\mathrm{K}$ indices align with the $\mathrm{x}, \mathrm{y}, \mathrm{z}$ coordinate axis. The $\mathrm{I}, \mathrm{x}$ direction was axial or along the length of the RBCC duct. The $J$, $y$ direction was vertical (height) and $K, z$ direction was depth of the RBCC duct.

Table 1. Nodes in Each Zone.

\begin{tabular}{|c|l|c|}
\hline Zone & \multicolumn{1}{|c|}{ Region } & Nodes \\
\hline 1 & Air inflow & $39 \times 41 \times 31$ \\
\hline 2 & Air inflow & $31 \times 41 \times 31$ \\
\hline 3 & Air flow above rocket & $61 \times 21 \times 15$ \\
\hline 4 & Rocket exit and Mixer & $71 \times 61 \times 15$ \\
\hline 5 & Mixer & $91 \times 61 \times 15$ \\
\hline 6 & Mixer and Diffuser & $91 \times 61 \times 15$ \\
\hline 7 & Diffuser & $38 \times 61 \times 15$ \\
\hline 8 & Afterburner injection & $41 \times 98 \times 15$ \\
\hline 9 & Afterburner and nozzle & $71 \times 61 \times 15$ \\
\hline 10 & Freestream & $21 \times 61 \times 15$ \\
\hline 11 & Freestream & $21 \times 15 \times 29$ \\
\hline 12 & Freestream & $21 \times 75 \times 29$ \\
\hline
\end{tabular}

The head end includes one half of each of two of the air supply orifices. The symmetry planes cut the air supply orifices in half. For ease of grid mapping, equivalent area square orifices are used to model the circular orifices. The first two zones required relatively high grid density to define the air orifices and capture the inlet jet interactions. The remainder of the RBCC duct required $61 \mathrm{~J}$-planes and $15 \mathrm{~K}$-planes to define (half of) the hardware height and depth, respectively.

The blockage created by the rocket engine was modeled in the flow path; however, the rocket engine's internal flow path was not contained in the present computational domain. The rocket engine's internal flow computation was performed in another effort ${ }^{10}$. One quarter of the rocket engine's exit plane was discretized in the present domain. The rocket's exit plane contained $21 \times 15$ nodes. The rocket engine's base area and the passage above the rocket engine both contained $21 \times 15$ nodes. The constant area mixer and diffuser required 211 and 91 I-planes (of $61 \times 15$ nodes), respectively.

The afterburner injection holes were modeled as equivalent area square orifices to simplify the grid generation. The experimental hardware had seven orifices on each sidewall; therefore, three and one half holes were modeled in the computational domain requiring a zone of $41 \times 98 \times 15$ nodes. The remainder of the afterburner and the convergent nozzle required $55 \mathrm{I}$ planes (each 61×15). Three zones, totaling 60,000 nodes, were used to create the freestream region downstream of the RBCC nozzle.

\section{Boundary Conditions}

The experimental conditions modeled in this analysis were 'Case 3' in the PSU experimental dataset'. Case 3 was a DAB mode with the rocket engine operating at an 
oxidizer to fuel $(\mathrm{O} / \mathrm{F})$ ratio of eight and afterburner $\mathrm{GH} 2$ injection. The rocket engine, air, and afterburner GH2 flow rates are shown in Table 2. At these flow rates, the oxygen available in the direct connect air and the injected afterburner hydrogen were such that an overall $\mathrm{O} / \mathrm{F}$ ratio of eight resulted in the afterburner section of the RBCC.

Table 2. Experimental Flow Rates for Case 3.

\begin{tabular}{ccc}
\hline \hline Rocket Engine & & \\
\hline GO2 Flow & $0.276 \mathrm{~kg} / \mathrm{s}$ & $0.608 \mathrm{lbm} / \mathrm{s}$ \\
GH2 Flow & $0.0345 \mathrm{~kg} / \mathrm{s}$ & $0.076 \mathrm{lbm} / \mathrm{s}$ \\
Chamber Pressure & $3.45 \mathrm{e}+6 \mathrm{~N} / \mathrm{m}^{2}$ & $500 \mathrm{psia}$ \\
\hline \multicolumn{1}{c}{ Duct } & & \\
\hline Air Flow & $0.721 \mathrm{~kg} / \mathrm{s}$ & $1.59 \mathrm{lbm} / \mathrm{s}$ \\
GH2 Flow in Afterburner & $0.0021 \mathrm{~kg} / \mathrm{s}$ & $0.046 \mathrm{lbm} / \mathrm{s}$ \\
GO2 in Airflow & $0.167 \mathrm{~kg} / \mathrm{s}$ & $0.368 \mathrm{lbm} / \mathrm{s}$ \\
\hline \hline
\end{tabular}

In the computational model the air orifices were specified as subsonic, fixed mass flow boundaries. The air flow Mach number was approximately 0.6 with a total temperature of 275 degrees Kelvin (495 R). The rocket nozzle exit boundary condition was fixed at conditions as determined by a previous analysis ${ }^{10}$. The rocket nozzle exit flow was three-dimensional with an average Mach number of approximately 2.6 and static pressure of 1.04 atmospheres. The afterburner hydrogen injection orifices were specified as Mach 1.3 plug flow. The hydrogen total temperature was 300 degrees Kelvin (540 R).

The physical walls of the hardware were set as no-slip boundaries and the symmetry planes were specified as such. The zones downstream of the nozzle had a farfield boundary condition applied that maintained one atmosphere pressure on the boundary. The right-most face was set as an exit boundary.

\section{$\underline{\text { Results and Discussion }}$}

\section{Solution Convergence}

The CFD solutions typically required 5000 iterations to converge if started from a quiescent initialization. Solutions started from a previously converged solution would converge in 2000 iterations or less. The solutions were run multiprocessor across nine CPUs on an SGI with R10,000 $194 \mathrm{Mhz}$ processor chips. Due to unbalanced zone sizes, the net load was only 4 processes. $\mathrm{CPU}$ processor time requirements for this calculation were $440 \mu \mathrm{sec} /$ iteration/node. When run on the nine processors, a speedup of four was obtained such that the wall clock time was $110 \mu \mathrm{sec} /$ iteration/node.

With these computational speeds, a solution could be obtained from quiescent flow in 88 wall clock hours and from a restart in 35 hours. With careful reblocking of the domain to better balance the load between processors, the time required to obtain a solution should drop one third. Additionally, CFD is often best used to generate relationships between engineering variables through parametric studies. If this were the intent with this computation then judicious reduction in node count (by up to one quarter) would accelerate solution convergence times as well.

\section{Flow Field Overview}

Color contours of the static pressure and Mach number on the RBCC vertical centerline are shown in Fig. 2. The freestream zones downstream of the nozzle were omitted from these images. The direct connect air flow is visible on the left hand side of the images. The rocket engine plume is clearly visible on the horizontal centerline. Between the rocket engine exit and the afterburner hydrogen injection (the mixer and diffuser sections) the flow field was generally two-dimensional. Note the axial station at which the pressure begins to rise in the mixer was the same axial station at which the rocket engine plume attached to the upper (and lower) wall. The Mach number contours indicate that the flow was entirely subsonic as it entered the diffuser section of the duct. The afterburner hydrogen injection shows up clearly in the Mach number contours at the end of the diffuser. The Mach number contours indicate the flow was nearly choked at the throat. The average Mach number at the exit was approximately 0.85 .

\section{Static Pressure}

Fig. 3 compares the CFD calculated static pressure on the upper wall to experimental data. The experimental data shown here are two individual tests with nominal flow rates for the air, rocket engine and afterburner. The difference in pressure between the two tests is representative of the test-to-test variation in the data. The direct connect air flow is on the left hand side of this plot and is responsible for the spikes in pressure in that region. The rocket engine exit plane is at $0 \mathrm{~cm}(0 \mathrm{in}$.). The diffuser begins at $88.9 \mathrm{~cm}(35 \mathrm{in}$.) and ends at 177.8 $\mathrm{cm}$ (70 in.) where the hydrogen was injected. The nozzle exit is at $236.22 \mathrm{~cm}(93 \mathrm{in}$.).

The agreement between the analysis and experimental data is quite good from upstream of the rocket engine through the mixer and half way down the diffuser $(\sim 127$ $\mathrm{cm}(50 \mathrm{in})$.$) . Half way down the diffuser the rate of$ pressure rise in the CFD falls below that of the experimental data. CFD codes have exhibited similar behavior in the past on pump diffusers with area ratios between $2: 1$ and $3: 1$. No explanation or solution was found for this phenomena ${ }^{11}$. Several parametrics were tried to obtain better agreement with the test data in this region. Grid density was increased, different turbulence models were implemented, and adjustments were made in the air, rocket engine and hydrogen flow rates. None of these modifications improved the CFD's rate of the pressure rise in the diffuser. 
As a result of this difference in pressure rise in the second half of the diffuser, the pressure in the afterburner was $2.0 \%$ below the experimental value. The step down in pressure at $177.8 \mathrm{~cm}(70 \mathrm{in}$.) was a result of the hydrogen injection and subsequent combustion. similar decrease is visible in the experimental data. The sharp decrease beginning at $228.6 \mathrm{~cm}$ (90 in.) was caused by the flow accelerating through the nozzle.

\section{Thrust and Specific Impulse}

The experimental thrust and specific impulse $\left(\mathrm{I}_{\mathrm{sp}}\right)$ data are compared to those from the same two test points used for the pressure data. For these two test points the average thrust generated by the experimental hardware was $1185.8 \mathrm{~N}\left(266.6 \mathrm{lbf}\right.$ ) and the average $\mathrm{I}_{\mathrm{sp}}$ was 366.6 seconds. Net CFD thrust was calculated by integrating the flow field at the nozzle exit plane. The CFD analysis produced a thrust of $1157.9 \mathrm{~N}(260.33 \mathrm{lbf})$ and an $\mathrm{I}_{s p}$ of 357.4. These are 2.4 and 2.5 percent below the experimental values respectively. The largest factor in the low thrust and $I_{\mathrm{sp}}$ was the $2.0 \%$ low afterburner pressure.

\section{Mixing}

Fig. 4 compares the CFD calculated mole fraction distributions to the experimental Raman spectroscopy data at four axial stations. The experimental data was collected via multiple instantaneous measurements for each specie at each axial station. The measurements were then averaged and analyzed to obtain species concentration profiles for each specie ${ }^{1}$. The four species measured were water, oxygen, nitrogen and hydrogen.

The four axial stations correspond to the second through fifth windows in the constant area mixer section of the duct. In these plots the flow is from left to right. The dark bar on the vertical axis of the plots indicates the width of the rocket exit. The Raman spectroscopy measurement indicates significant amount of hydrogen in the RBCC duct. This, however, is an artifact of the Raman spectroscopy measurement technique. Hydrogen is not thought to be present at such levels in the experimental flow. The presence of the hydrogen signal does not significantly affect the calculated mole fractions of the other three species.

The agreement between the CFD and the test data is fairly good at the second, third and fourth windows. At the fifth window, the CFD profiles indicate the computed flow was less thoroughly mixed than the experimental flow.

\section{Conclusions}

The FDNS CFD code has been benchmarked for a June 2000 .

$\mathrm{H} 2 / \mathrm{O} 2 \mathrm{RBCC}$ rocket-ejector mode in DAB operation. Additionally, the results show that FDNS can be used as a predictive/engineering tool for an $\mathrm{RBCC}$ internal flow path. The computed static pressure axial distribution matched the test data except in the afterburner where it fell 2.0 percent low. The thrust and $\mathrm{I}_{\mathrm{sp}}$ were 2.4 and 2.5 percent low, mainly due to the low afterburner pressure. The computed mixing of the rocket engine plume with air agreed well with the test data.

\section{Acknowledgments}

The author would like to thank Jeff West for his assistance with this work.

\section{References}

I Lehman, M., Pal, S., Santoro, R., "Experimental Investigation of the RBCC Rocket Ejector Mode," AIAA Paper 2000-3725, July 2000.

2 Holt, J.B., and Ruf, J.H., "FDNS CFD Code Benchmark for RBCC Ejector Mode Operation," PSU PERC $11^{\text {th }}$ Annual Symposium, November 1999.

${ }^{3}$ Wang, T.-S. and Chen, Y.-S., "Unified Navier-Stokes Flowfield and Performance Analysis of Liquid Rocket Engines," Journal of Propulsion and Power, Vol. 9, No. 5, Sept-Oct 1993, pp.678-685.

${ }^{4}$ Chen, Y.-S., Liaw, P., Shang, H.-M. and Chen, C.P., "Numerical Analysis of Complex Internal and External

Viscous Flows with a Second-Order Pressure-Based Method," AIAA Paper 93-2966, July 1993.

${ }^{5}$ Chen, Y.-S. and Kim S.W., "Computation of Turbulent Flows Using an Extended $\kappa-\varepsilon$ Turbulence Closure Model," NASA CR-179204, Oct. 1987.

${ }^{6}$ Chen, Y.-S., Cheng, G.C. and Farmer, R.C., "Reacting and Non-Reacting Flow Simulation for Film Cooling in 2-D Supersonic Flows," AIAA Paper 92-3602, July 1992.

7 Liakopouls, A., "Explicit Representations of the Complete Velocity Profile in a Turbulent Boundary Layer," AIAA Journal, Vol. 22, No. 6, Jan. 1984, pp. 844-846.

${ }^{8}$ Wang, T.-S. and Cornelison, J., "Analysis of Flowfields over Four-Engine DC-X Rockets," AIAA Paper 96-2953, July 1995.

${ }^{9}$ Wang, T.-S., McConnaughey, P., Warsi, S., and Chen, Y.-S., "Computational Pollutant Environment Assessment from Propulsion System Testing," Journal of Spacecraft and Rockets, Vol. 33, No. 3, May-June 1996, pp.386-392.

${ }^{10} \mathrm{Pal}, \mathrm{S}$., Tucker, T., Lehman, M., and Santoro, R., J., "Experimental Studies of Heat Transfer in Rectangular Nozzles for CFD Design Methodology" $33^{\text {rd }}$ ASME/AIChE/ANS/AIAA National Heat Transfer Conference, August 1999, PAL 252.

$"$ Garcia, R., NASA, MSFC, Personal Communication, 


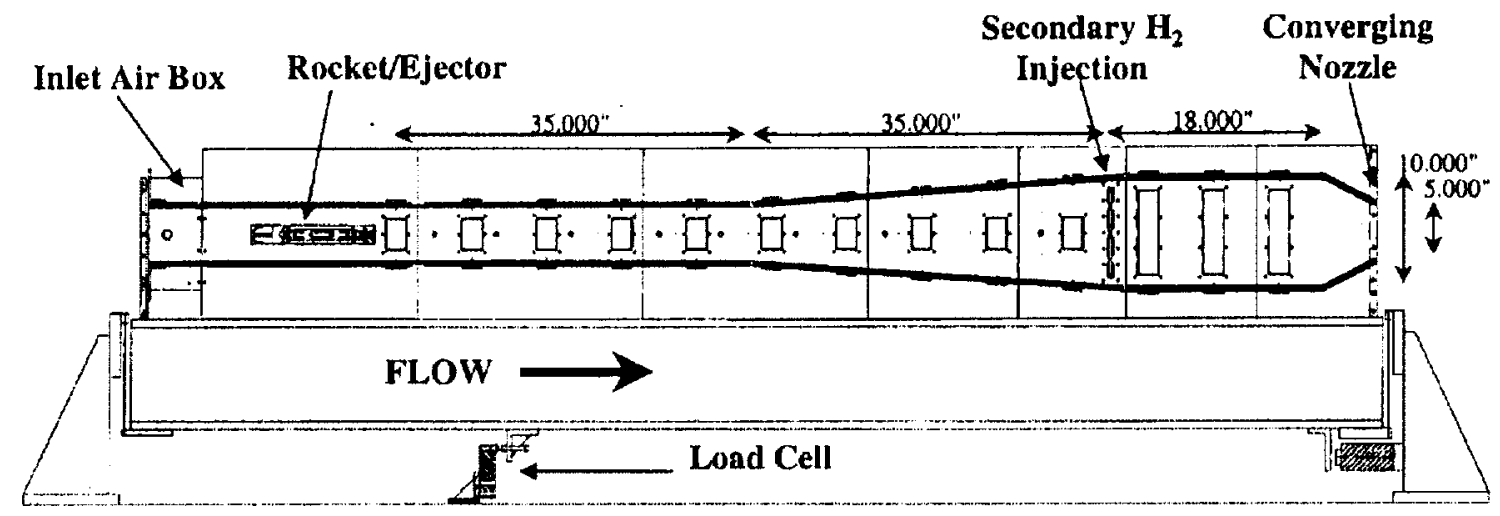

Fig. 1 The PSU RBCC Direct Connect Experimental Hardware. 


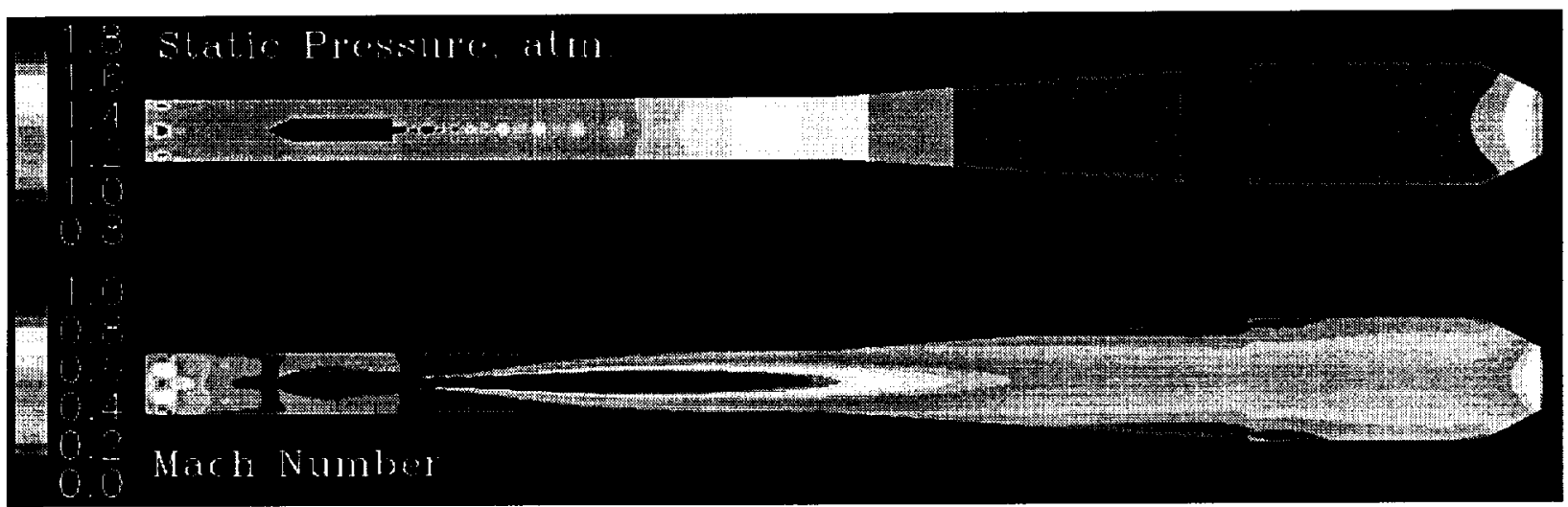

Fig. 2. Calculated Static Pressure and Mach Number Contours on Centerline of RBCC.

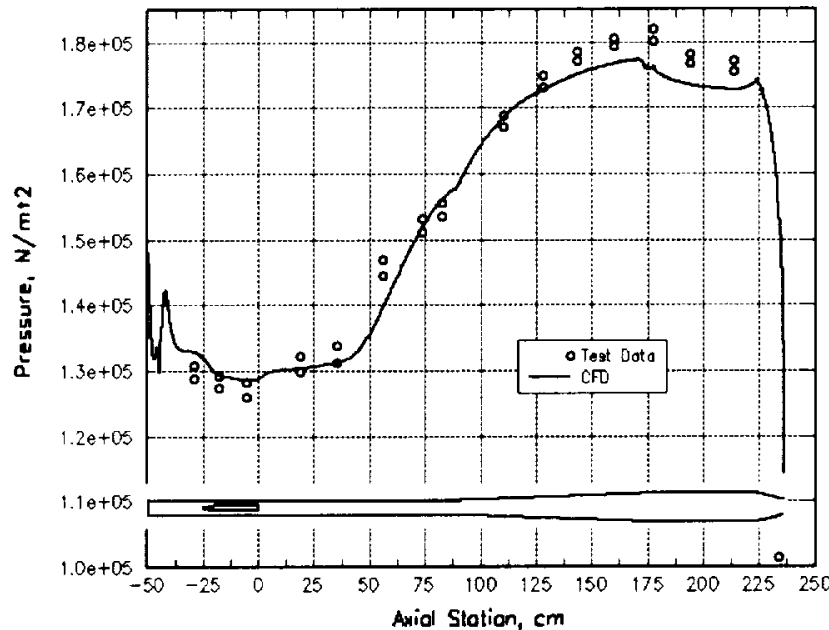

Fig. 3 Static Pressure Comparison

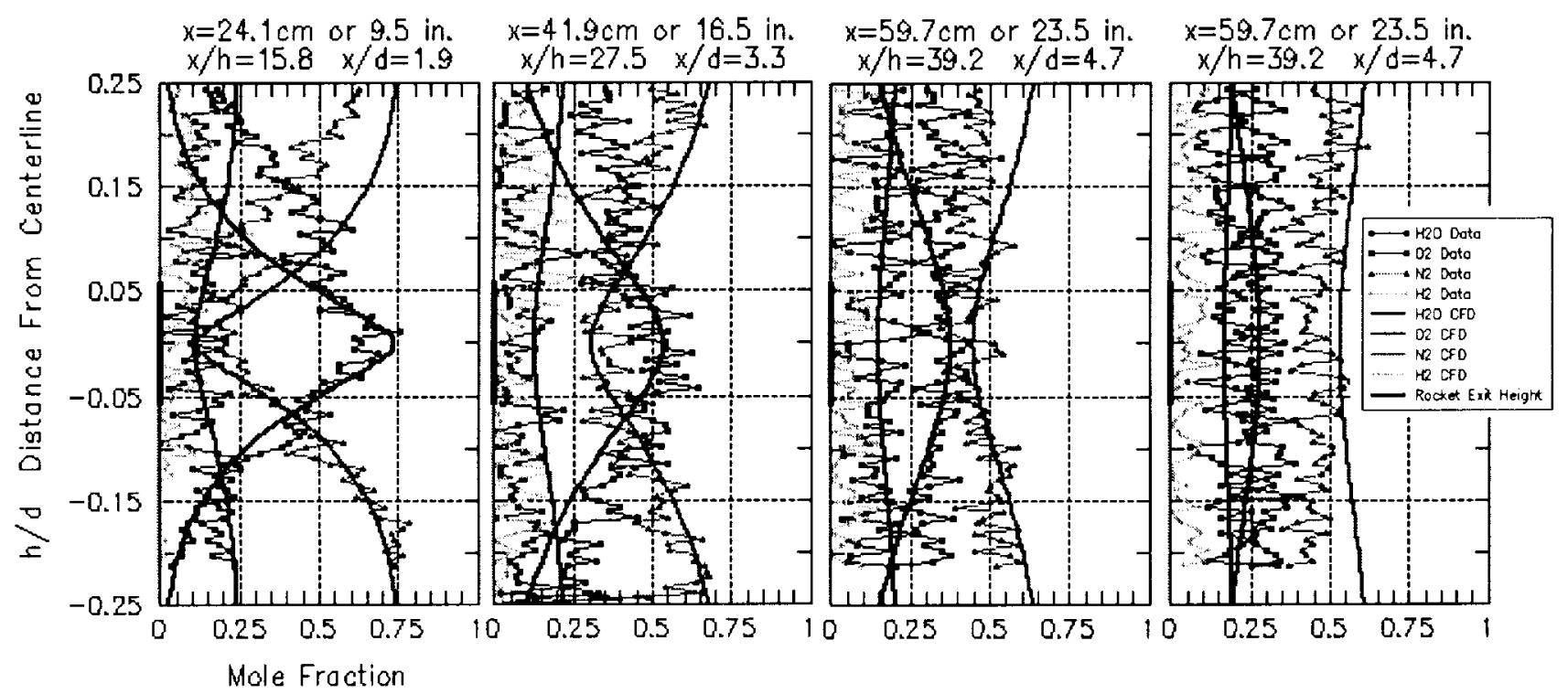

Fig. 4 Mole Fraction Comparison 